\title{
A classification framework for out-of-home advertising media in South Africa
}

\author{
Thérèse Roux, De la Rey van der Waldt and Lené Ehlers*
}

\begin{abstract}
Out-of-home $(\mathrm{OOH})$ advertising media have expanded worldwide and the shape and format of these media globally, as well as in South Africa, have changed considerably. Until recently, the $\mathrm{OOH}$ advertising media landscape consisted primarily of outdoor advertising or billboards reaching vehicular traffic, but now has expanded to include a wide range of $\mathrm{OOH}$ advertising media types which aim to reach a mobile audience wherever they live, work, play, drive, shop or commute. Currently there is no coherent contemporary framework to compare and select the most effective media options to reach a selected target market in a specific $\mathrm{OOH}$ audience environment. This article draws from academic and practitioner sources to propose a classification framework for $\mathrm{OOH}$ advertising media in South Africa comprising four major platforms: outdoor advertising, transit media advertising, street-and-retail furniture advertising, and digital and ambient $\mathrm{OOH}$ media channels. The framework serves to inform marketers of viable and cost-effective traditional and contemporary $\mathrm{OOH}$ advertising media options. It also indicates what platforms are appropriate to reach specific audiences effectively in a variety of environments outside their homes. This is the first framework of its kind for the South African context that offers an orderly, integrated basis for future research.
\end{abstract}

Keywords: advertising media, ambient out-of-home advertising, digital out-of-home advertising, media integration, media synergy, outdoor advertising, out-of-home advertising media, street-and-retail furniture advertising, transit advertising

\section{INTRODUCTION}

Out-of-home $(\mathrm{OOH})$ advertising media no longer encompass only outdoor advertising spaces. The concept of outdoor advertising emphasises the open air or outdoors aspect of this type of advertising that one encounters when leaving the home or workplace, such as advertising seen from a car or taxi, in a bus or a train (Gambetti 2010, 37). Lately there has been a growing preference to use the broader concept, namely $\mathrm{OOH}$ advertising media. This concept includes outdoor advertising in the public domain as well as other non-domestic $\mathrm{OOH}$ advertising - not necessarily outdoor communication - such as advertising at airports, train and subway stations and entertainment or retail venues like shopping malls, health clubs, doctors' rooms, public restrooms and restaurants (Gambetti 2010, 37; Wilson and Till 2008, 59). For the purpose of this article, $\mathrm{OOH}$ advertising media include four major platforms: outdoor advertising media; street-and-retail furniture advertising media; transit advertising media and alternative $\mathrm{OOH}$ advertising media.

$\mathrm{OOH}$ advertising media are probably the oldest form of advertising, and can be traced back a few thousand years BC to commercial messages depicted on ancient rock-art paintings in India and inscriptions and graffiti in Egypt and Greece (Veloutsou and O'Donnell 2005, 218). The earliest $\mathrm{OOH}$ advertising media were, in their original form, some type of message displayed outdoors to

* Dr Thérèse Roux was a student at the Department of Marketing, University of Pretoria, South Africa: Email: rouxat@tut. ac.za; Prof. De la Rey van der Waldt, Department of Public Relations and Business Communication, Tshwane University of Technology, Pretoria, South Africa. E-mail: vanderwaldtD@tut.ac.za; Dr. Lené Ehlers, Department of Marketing, University of Pretoria, South Africa. E-mail: lene.ehlers@up.ac.za 
communicate to the public. Writing outdoor messages on papyrus about lost and found goods was common practice in ancient civilisations, and such messages may still be seen on display in the Louvre on papyrus dated to $146 \mathrm{BC}$ - with a message offering a reward for finding two escaped slaves from Alexandria (Symons 2004, 39). There were also proclamations on tablets on walls in ancient Greece and Rome, as well as signs with symbols - such as a goat for dairy products, or a bush for a tavern - in Greece (Bernstein 2005, 12). Alternative forms of early $\mathrm{OOH}$ advertising in Europe included royal and government decrees announced by town criers during the second half of the $12^{\text {th }}$ century, promotional handbills during the second half of the $15^{\text {th }}$ century, and early versions of theatrical posters in the late $17^{\text {th }}$ century (Brioschi in Gambetti 2010, 17).

Not surprisingly, $\mathrm{OOH}$ advertising media have changed and developed over time, and the shapes and formats of this medium have continued to evolve even more during the past century. Until relatively recently, $\mathrm{OOH}$ advertising media consisted prim arily of outdoor advertising or billboards, but these have expanded to some alternative $\mathrm{OOH}$ advertising media platforms such as transit advertising media (Duncan 2005, 376; Lane, King and Reichert 2011,359; Moriarty, Mitchell and Wells 2012, 367; O'Guinn, Allen and Semenik 2000, 507; Shimp 2010, 585, Sissors and Baron 2010, 263; Yeshin 2006, 238) and street-and-retail furniture advertising media (Shimp 2010, 586). Even more recently, various other options have been introduced to include a variety of digital and ambient $\mathrm{OOH}$ advertising media such as advertising messages on goods used or displayed in public places, Bluetooth posters and touch-screen interactive panels (Gambetti 2010, 34; Moriarty et al. 2012, 365; Shimp 2010, 580).

Due to the fast and recent evolution, as well as the wide variety available, there is some disagreement in the literature on exactly what constitutes contemporary $\mathrm{OOH}$ advertising media. Some sources only regard advertising that is outdoors as part of $\mathrm{OOH}$ advertising media (Koekemoer 2005, 200; O'Guinn et al. 2000, 507; Shimp 2003, 356; Yeshin 2006, 328), while others include some indoor marketing communication such as sales promotions, in-store radio, cinema advertising and product placement in this class (Duncan 2005,376; Gambetti 2010,36). Only a few sources acknowledge that just like other media, $\mathrm{OOH}$ advertising media are now entering the digital era (Belch and Belch 2012, 449; Lane et al. 2011, 359; Sissors and Baron 2010, 441), thereby ignoring the latest developments in this medium.

\section{PROBLEM STATEMENT}

Current views often still focus on traditional $\mathrm{OOH}$ advertising boards in the roadside environment, disregarding other more contemporary formats such as those at airports, in public transport waiting areas, at minibus taxi ranks, along pedestrian routes, in shopping malls and in leisure environments. No proper classification framework for a holistic range of $\mathrm{OOH}$ advertising media options in South Africa exists. Without such a classification system there is no orderly, integrated basis to describe and research this advertising medium, nor is there a complete understanding of the wide range of contemporary $\mathrm{OOH}$ advertising media options. The practical implications are 
that the unique characteristics and potential benefits of different platforms, such as street-and-retail furniture advertising media and alternative $\mathrm{OOH}$ advertising media, might not be appreciated by some advertisers. Furthermore, the leading role that $\mathrm{OOH}$ advertising media can play in influencing consumers' shopping behaviour is not recognised. Likewise, the opportunity to reach very specific market segments at a variety of locations, such as shopping malls, golf courses, outdoor squares, festivals and events, access routes to shopping malls and stores, health clubs, beaches, schools, public restrooms, doctors' waiting rooms, sports stadia and arenas are not fully exploited (Gambetti 2010, 36; Lane et al. 2011, 374; Sissors and Baron 2010, 269).

Few sources consider the application of $\mathrm{OOH}$ advertising media in the South African context (Du Plessis, Bothma, Jordaan and Van Heerden 2010, 107; Du Plooy and Du Plessis 2011, 756; Koekemoer 2005, 200; Nagel and Louw 2004, 98; Pauwels 2005, 337). Some of these sources, such as Du Plessis et al. (2010, 107) and Koekemoer $(2005,200)$, focus on outdoor advertising media but do not include any of the more contemporary $\mathrm{OOH}$ advertising media types. Older published South African studies focused only on specific types of $\mathrm{OOH}$ advertising media, such as free-standing outdoor advertising media, also referred to as billboards by Nagel and Louw $(2004,98)$ and Pauwels $(2005,337)$, and more recently minibus taxi advertising, as highlighted by Du Plooy and Du Plessis $(2011,756)$. However, none of these South African sources followed a holistic perspective to categorise or order all the different types of $\mathrm{OOH}$ advertising media currently available in the country.

\section{RESEARCH QUESTION, OBJECTIVES AND METHOD}

In the light of the above discussion the authors seek to answer the following research question: How can the different types of $\mathrm{OOH}$ advertising media be classified, and how do the major $\mathrm{OOH}$ advertising media platforms compare?

The aim of this article is to describe the context and classification of $\mathrm{OOH}$ advertising media. The objective is to propose a classification framework for $\mathrm{OOH}$ advertising media in South Africa, and to provide a comparison of the characteristics of the major $\mathrm{OOH}$ advertising media platforms.

A literature study was conducted to reach the above objectives. Babbie and Mouton $(2005,457)$ indicate that a literature review aims to refine and deepen a theoretical framework. It is also aimed at finding out what has been done in a particular field of study, in order to familiarise the researcher with the latest developments in the area of research, as well as related research areas. The results obtained by previous researchers are used as a basis for new research.

Fouché and Delport $(2009,124)$ explain that a literature review serves the function of identifying some deficiencies in extant research and suggest the way forward for further research. Machi $(2009,200)$ adds that resolving conflicts among apparently contradictory existing studies is a crucial purpose of any review. The authors of this article propose a new classification framework for $\mathrm{OOH}$ advertising media aimed at overcoming an identified gap in the extant literature. 
Some prominent international journals (Journal of Advertising Research, Journal of Current Issues and Research in Advertising, Journal of Advertising, International Journal of Advertising), considered to be major publishers of research on advertising media (Cheong and Kim 2012,323), were examined to find a classification of $\mathrm{OOH}$ advertising media types. The South African Bibliography Network (SABINET) was used to search for appropriate South African journal articles. The articles from these sources did not offer a comprehensive classification of contemporary $\mathrm{OOH}$ advertising media types, but rather focused on the effectiveness of specific $\mathrm{OOH}$ advertising media types, such as outdoor advertising boards and posters (Nagel and Louw 2004; Pauwels 2005; Van Meurs and Aristoff 2009), digital $\mathrm{OOH}$ advertising (Osborne and Coleman 2012), airport advertising media (Wilson and Till 2008) and taxi advertising media (Veloutsou and O'Donnell 2005).

The classifications found in some of the most prominent textbooks on advertising and marketing communication published during the past decade were also examined, but these do not apply to the contemporary $\mathrm{OOH}$ advertising media types used in the South African context (Belch and Belch 2012, 578; Du Plessis et al. 2010, 107; Duncan 2005, 372; Koekemoer 2005, 200; Lane et al. 2011, 359; Moriarty et al. 2012, 364; O'Guinn et al. 2000, 507; Shimp 2000, 356; Sissors and Baron 2010, 441; Wells et al. 2006, 227; Yeshin 2006, 328).

The list of $\mathrm{OOH}$ advertising media associations from FEPE (Federation European Publicite Exterieura) International Worldwide association of $\mathrm{OOH}$ advertising media companies was screened, in order to present some perspective on how the global $\mathrm{OOH}$ advertising industry categorises this wide variety of media types. These are the officially recognised trade associations for the $\mathrm{OOH}$ advertising media industry in their respective countries; they provide connectivity with members in the industry and typically represent the majority of industry revenues (FEPE International 2013).

Only the official web pages of members with an English classification for the different formats were then examined - specifically, the Out-of-Home Media Association of South Africa (OHMSA 2013), the Outdoor Media Association of New Zealand (OMANZ 2013), the Outdoor Media Association of America (OAAA 2013), the Outdoor Media Association of Ireland (OMA Ireland 2013), the Out of Home Marketing Association of Canada (OMAC 2013), the Outdoor Media Association of Australia (OMA Australia 2013) and the Outdoor Media Centre of the United Kingdom (OMC 2013). The listed associations for countries such as Finland and Germany did not offer a classification framework in English on their web page, and were thus not included for the purposes of this article (FAW 2013; Outdoor Finland 2013).

Information from all these sources was drawn on, in order to propose a classification framework of $\mathrm{OOH}$ advertising media in the context of South Africa, which is discussed extensively hereunder.

\section{CLASSIFICATION OF OOH ADVERTISING MEDIA IN SOUTH AFRICA}

The academic literature on $\mathrm{OOH}$ advertising media of the past decade, as well as the view of some prominent $\mathrm{OOH}$ advertising media associations across the globe, as it relates to exactly what forms 
part of $\mathrm{OOH}$ advertising media, constituted the foundation of the new proposed classification. The focus in this framework is on the application of these media in the South African environment.

The proposed classification of the $\mathrm{OOH}$ advertising media in South Africa comprises four major $\mathrm{OOH}$ media platforms: outdoor advertising media, transit media advertising, street-andretail furniture advertising, and alternative $\mathrm{OOH}$ advertising media (see Figure 1). Each of these major platforms, in turn, comprises media formats and media vehicles. For example, the outdoor advertising media platform constitutes two media formats, namely: outdoor advertising on constructions/buildings and free-standing outdoor advertising. A media vehicle refers to a specific type of sign at a specific location or environment. For example, a $4 \mathrm{~m} \times 5 \mathrm{~m}$ super sign next to the $\mathrm{N} 1$, on the highway between two specific off-ramps.

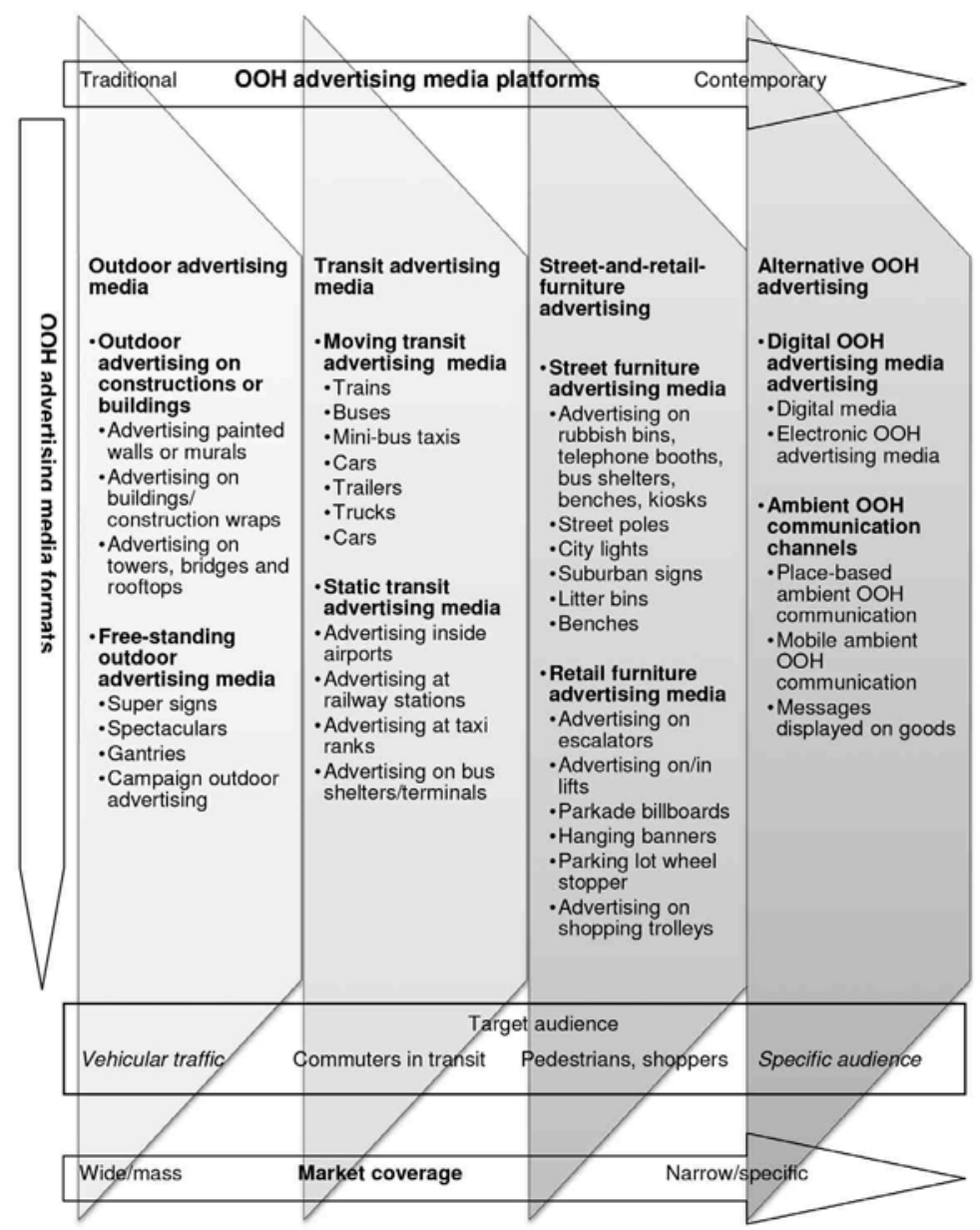

Figure 1: Classification of the $\mathrm{OOH}$ advertising media in South Africa 
The most original or traditional platform is outdoor advertising media (on the left), while the most contemporary platform is alternative $\mathrm{OOH}$ advertising media (on the right), comprising digital or electronic formats and ambient $\mathrm{OOH}$ media. $\mathrm{OOH}$ advertising media will continue to diversify over the next decades, not only because of their cost-effectiveness, but also because $\mathrm{OOH}$ advertising seems to be the only available realm from which to reach progressively elusive consumers, and is the ideal anchor for integrated marketing communication (IMC) campaigns (Lopez-Pumarejo and Myles 2009, 38).

The classification provides, for each platform, the two main formats in addition to examples of each. It also indicates the respective intended audiences. Outdoor advertising media are primarily aimed at vehicular traffic. Transit media advertising reaches commuters in transit. Street-and-retail furniture advertising media reach pedestrians and shoppers. Alternative $\mathrm{OOH}$ advertising media target certain audience profiles where particular groups congregate for specific purposes, such as at doctors' rooms, public health clinics, in shopping malls, restaurants, nightclubs, classrooms, on golf courses, or at sports and cultural events. Outdoor advertising media reaching mass vehicular traffic offer the broadest market coverage, while alternative $\mathrm{OOH}$ advertising media are better suited for targeting narrow or very specific audience profiles. Improvements in technology will allow advertising to be even more specific in targeting audiences in the future.

Sales promotions and cinema advertising do not form part of $\mathrm{OOH}$ advertising media in this classification, since sales promotions are typically regarded as part of traditional promotion (Du Plessis et al. 2010, 228), while cinema is regarded as a broadcast or traditional medium (Lane et al. 2011, 424; Wells et al. 2006, 249). Furthermore, store signage on the premises or attached to a store does not fall within the scope of $\mathrm{OOH}$ advertising media either, because the advertising space is used by the store owners or retailers themselves to identify their store and attract customers. The focus of the article is on off-premise $\mathrm{OOH}$ advertising media, as used by third-party advertisers or product and service retailers, and by manufacturers of consumer-oriented brands.

The characteristics, major types, benefits and limitations of each of the four platforms, together with suggestions for increasing their effect, are discussed next.

\section{Outdoor advertising media platforms}

Contemporary outdoor advertising refers to all large-format advertising displays viewed from the road; and it is typically intended for viewing from extended distances by vehicular traffic, while driving (Shimp 2010, 578). Outdoor advertising is one of the most popular OOH advertising mediums in South Africa, if the advertising expenditure is compared to that spent on other types of media in this class (Adindex in Provantage 2010). Outdoor advertising comprises two formats: outdoor advertising on constructions/buildings and free-standing outdoor advertising signs/ billboards. Outdoor advertising on constructions/buildings utilises existing urban structures to host advertising, for instance around construction sites, on existing buildings/walls, or on towers and 
bridges (SAMOAC 2010, 15). This means no new or additional advertising structures are erected in the urban environment - since these formats are often temporary or are attached to existing buildings, they leave no long-term impact on the environment.

Outdoor advertising signs on highways and major arterial roads are typically used by advertisers as mass media aimed at reaching a broad market of motorists and commuters who spend long periods in traffic on weekdays. Vehicular traffic is repeatedly exposed to such advertising messages for longer periods, resulting in very high-frequency viewing (Bhargava, Donthu and Caron 1994, 54). This media platform offers geographic flexibility which other media do not, since it can be used effectively on a national, regional or local basis (Taylor and Franke 2003, 159). National advertisers globally, and in South Africa, often use it to maintain top-of-the-mind awareness for their brand or to support the messages of IMC campaigns sent by other advertising media (Davidson 2001, 89; Katz 2010, 89). Many local businesses prefer to use outdoor advertising rather than the mass media, because it can provide targeted exposure to their specific geographic markets, without any wasted exposure (Wells et al. 2006, 229).

Advertising on huge outdoor advertising formats, such as spectaculars, super signs, wall murals or building wraps, could add importance or brand status by projecting an image with authority for the brand being displayed (Bernstein 2005, 114). The high-impact larger-than-life size of outdoor advertising is seen as a major strength of the medium (Katz 2010, 91; Sissors and Baron 2010, 277). In South Africa, the potential impact of such super large outdoor advertising formats, such as wraps around buildings or constructions, has only recently begun to be exploited. The broad reach and high levels of frequency obtained by outdoor advertising are further reasons for using this platform (Du Plessis et al. 2010, 107; Lane et al. 2011, 361). This is a result of its ability to deliver repeated, permanent exposures of the message to the mobile part of a population, 24 hours a day (Shimp 2010, 581). Such repeated exposure has been shown to have a significant effect on the level of recall of those consumers living/working in the area where the advertisements are placed (Bhargava, Donthu and Caron 1994, 54).

Research has found that in general, South Africans' attitudes towards outdoor advertising are positive when it comes to this medium, which is considered to be a plus (Nagel and Louw 2004; Pauwels 2005). Nagel and Louw (2004) investigated the response of black South Africans towards outdoor advertising in Limpopo (a semi-urban rural area), by conducting personal interviews. The study found that although the majority of respondents had positive attitudes towards outdoor advertising in general, they disapproved of the Westernised approach of the advertising agencies creating these communication messages. Some of the imagery or verbal content employed (for example, depicting black bow ties, fiery flames, or hops in alcohol advertising, or using unfamiliar words such as 'diva') did not communicate the desired information or make the right impression with the target audience. The successful interpretation of a message was clearly influenced by the culture and frame of reference of the receivers. It is therefore suggested that advertisers customise their designs and messages for the local communities they target. 
Pauwels $(2005,337)$ investigated the effectiveness of outdoor advertising used to communicate TB- and HIV/AIDS-related messages to South Africans. The purpose of the study was to determine how the general principles of message design could be applied in a multicultural South Africa. The results suggested that outdoor advertising should be used to communicate a single, strong message, together with other elements of the marketing communication mix, thereby reinforcing in-depth information (face-to-face counselling and health-related brochures). Both South African studies suggest that it is necessary to tailor an outdoor advertising message and communication mix to a local audience, market segment or ethnic group.

One of the limitations of outdoor advertising is that due to mobility and speed, audience exposure to the message is brief. This limits the message capabilities and it therefore requires the use of a limited number of words/illustrations, as well as simple messages (Moriarty et al. 2012, 365). In addition, the limited demographic selectivity of outdoor advertising can result in waste coverage through exposure to people who are not part of the target market. Advertisers therefore often use other media such as magazines and radio to better pinpoint the selected audience. Too much or unattractive and distasteful outdoor advertising pollutes the environment. It also attracts less attention from vehicular traffic, thereby decreasing the audience's potential exposure to the advertising message (Shimp 2010, 583).

\section{Transit advertising media platforms}

Transit advertising is typically aimed at commuters making use of transport services on a daily basis (buses, taxis, commuter trains and aeroplanes). The transit advertising platform consists of moving transit advertising media and static/stationary advertising. Moving transit advertising media include displays affixed to the outside or inside of moving vehicles, trains, buses or taxis. Static/ stationary advertising is positioned in the common areas of train stations, taxi ranks, terminals and airports. Transit advertising is suitable for advertisers who wish to target adults who live and work in major metropolitan areas. It is considered an effective means of delivering wide coverage to a large number of people, as well as detailed, repetitive messaging, by placing it along specific routes or at specific stations (Moriarty et al. 2012,367). Transit advertising media can also be used creatively, and they have the potential to bring the advertiser's message directly to a wide variety of commuters, whereas outdoor advertising may be restricted or not as effective (Provantage 2010). Minibus taxi and public transit advertising media can, for instance, be employed to reach the emerging market travelling back and forth to major metropolitan areas on a daily basis. These commuters are part of a captive audience when waiting at train stations, bus stops, taxi ranks, as well as while travelling to their destinations. This may offer audiences more time to notice and be discerning about their surroundings and about advertising messages, compared to drivers who typically pass outdoor advertising boards at high speed, or to vehicle passengers, to whom such 
Transit advertising media probably have to compete for attention with numerous distracting stimuli in the transit environment, which can result in wasted media coverage to people who are not part of the target market (Sissors and Baron 2010, 266). It can also be difficult for advertisers to use transit media to engage with daily commuters, because they may be tired, bored or too absorbed in their thoughts to even notice a message (O'Guinn et al. 2000, 588). Therefore, transit advertising is used predominantly as a secondary or support advertising medium, since it works best in conjunction with other mediums.

Timms (2012) notes that several large advertisers have recently employed transport advertising media in South Africa to launch new brands and products, and to reinforce existing brands. Advertisers such as Coca-Cola, PEP, Nedbank and Samsung have utilised transit advertising as part of their overall IMC strategy to reinforce their brand message, sponsor specific events, and communicate existing campaign messages to maintain top-of-the-mind awareness. Telecommunication brands such as 8.ta, Cell $\mathrm{C}$ and Vodacom have also recently extensively used transit advertising media to reinforce the launching of some of their latest offerings. New brands or new product launches frequently use transit advertising media as part of their original launch strategy, or as a platform to reinforce their communication.

The public transport system in South Africa is expected to change drastically, in line with government's national transport master plan, which is a blueprint for transport infrastructural development and investment over the next 45 years. Government funding is being used to establish a fully integrated transport system through the development of new infrastructure, and the upgrading of existing transport infrastructure that should establish a world-class transport system (Provantage 2010). The national transport master plan recently commenced with the 2010 Soccer World Cup transportation infrastructure upgrade. Various other projects are underway, such as the taxi recapitalisation process, the SARCC (the South African Rail Commuter Corporation) integration, the new upmarket Gautrain, the bus rapid transport system development, and general road and e-toll development projects (Timms 2012). In future, the role of this $\mathrm{OOH}$ advertising media platform will probably become even more important for advertisers, as road transport commuters switch to new public transport options.

The nature of public transit advertising media (and in particular minibus taxi transport) in South Africa differs considerably from that of developed countries, judging from the discussions and research projects published on the topic (Veloutsou and O'Donnell 2005, 202; Wilson and Till 2008, 58). Public transport systems in these countries are well developed in urban centres, and widely used by the broad public. In South Africa, minibus taxis are the most popular mode of transport in urban areas, used by the majority of the population. The minibus taxi industry is not part of the public transport sector, but currently carries 65 per cent of South African commuters, mainly comprising the black emerging market (Provantage 2011). Minibus taxis each transport up to 16 passengers, whereas in European countries smaller taxis transport only a few passengers at a time. Minibus taxi commuters are seen as a captive audience within a controlled environment, 
given that they spend on average about 58 minutes daily inside a taxi - where they are exposed to advertising media. This emerging market makes use of a combination of transport, such as buses, minibus taxis, trains and motor vehicles. More than one mode of transport is often used to reach work/home on a daily basis (Du Plooy and Du Plessis 2011, 756).

Research by ComutaNet (a transit advertising media company) revealed important aspects of consumer behaviour when it comes to minibus taxis commuters. In South Africa, 19 million people commute daily. A large percentage of them leave home before 06:00 and return after 18:00. This leaves limited time for exposure to traditional media. Every day, commuters spend more than an hour in taxis or waiting at taxi ranks. Furthermore, the average income of this emerging class is rising year on year. Their spending is no longer limited to basic products, but now includes luxury brands and products (ComutaNet 2011).

Du Plooy and Du Plessis $(2011,764)$ assessed the effectiveness of minibus taxi advertising in South Africa by interviewing regular minibus taxi commuters on their attitudes, perceptions and the attention given to minibus taxi advertising. The results showed that the captive audience had strong positive feelings about advertising in general, that they enjoyed looking at advertisements and found this pastime entertaining. This correlates with the findings of Veloutsou and O'Donnell $(2005,217)$, who assessed the responses of taxi cab commuters in Scotland. The South African study suggested that an integrated approach be followed in utilising traditional advertising media combined with $\mathrm{OOH}$ media, and specifically taxi advertising, to reach this emerging market. This uniquely South African medium is ideal for reaching the emerging market, in that it targets pedestrians, drivers and passengers in specific areas, offering a combination of mobility and visual impact.

Transit advertising includes static advertising found at airports and in public transport areas such as stations, platforms and terminals. Airport advertising represents 17 per cent (Adex in Provantage 2010) of OOH expenditure in South Africa, and includes interior and exterior airport displays. Interior airport displays are located throughout terminals in the arrivals and departures areas, ticketing areas, baggage-claim areas, gate-hold rooms, concourses, entrances/exits, retail stores and VIP lounges. Exterior airport displays appear along airport and terminal roadways in the form of billboards, spectaculars or overhead signs (Provantage 2010).

Airport advertising offers a unique environment for advertisers to reach a captive audience of international and domestic business and leisure travellers. The specific placement or location of advertisements inside airports is crucial for success. Advertisements should be placed strategically to build the brands of appropriate products or services, and to elicit direct response. Alternatively, they can be used to provide point-of-sale information, particularly related to car rental, accommodation or tourist attractions (Wilson and Till 2008, 70). Travellers are, however, often in a rush and are bombarded with messages, which means they may not be susceptible to advertising. It is therefore important to place media in transit environments, where travellers might spend more time and 
might be more receptive to advertising messages, such as in business lounges at airports or inside transit-media vehicles.

\section{Street-and-retail furniture advertising media platforms}

Not all $\mathrm{OOH}$ advertising media are large and directed at vehicular traffic or commuters. Smaller formats include street-and-retail furniture advertising, which consists of advertising on public facilities and structures (hence the name). These platforms include benches, street poles, elevators, lifts and kiosks - sites which are not primarily intended to be viewed by vehicular traffic, but are aimed at pedestrians, commuters or shoppers.

Street furniture advertising media allow for geographically targeted advertising in specific areas, and are especially effective for directing messaging to highly defined commuting and pedestrian audiences on specific roads in urban areas (Lane et al. 2011, 375). Smaller OOH advertising formats, such as street-and-retail furniture advertising, are allowed in suburban areas and pedestrian environments such as pedestrian streets, urban parks and open spaces, picnic sites, shoppingcentre parking areas, taxi ranks and other public transport nodes, where larger outdoor advertising media are not usually permitted by controlling authorities on national, provincial and local level (SAMOAC 2010, 25). Thus, such media are generally found in urban centres and pedestrian environments across South Africa. They are usually located at busy intersections on roads, close to office parks, shopping centres, taxi ranks and other public transport nodes. This platform offers a unique and cost-effective advertising opportunity in suburban areas. Its potential impact might, however, not be seen as good, compared to larger $\mathrm{OOH}$ advertising media formats such as large billboards or building wraps. The associated image might not be suitable for prestigious brands when advertising on rubbish bins or inside public bathrooms. For example, a bank advertisement placed inside a public bathroom or a fast-food advertisement on a rubbish bin might not result in the desired prestigious or appetising image.

Not all street furniture advertising is located on typical furniture/fixtures such as benches, shelters or kiosks. Other platforms such as street-poles, where small, illuminated advertisements are displayed on lamp-poles located on primary and secondary arterial roads in business and residential areas, target commuters in slow-moving automobiles as well as pedestrians. It is a very popular and widely used form of street-furniture advertising in South Africa (SAMOAC 2010, 25). Although such displays are relatively small, when used repetitively the consecutive signs in a row tell an intriguing story, which makes it a uniquely powerful advertising medium.

Retail furniture advertisements can be found close to points-of-purchase or central gathering points in the retail environment, and are primarily used to target potential shoppers (Primedia 2010). This category of $\mathrm{OOH}$ advertising media includes advertising on displays outside/inside shopping malls or convenience stores, on furniture/fixtures such as information kiosks, lifts, escalators, phone 
booths, bicycle-racks, parking booms and shopping trolleys, as well as other advertising media in the retail environment, such as posters/banners in parking areas or inside malls (OHMSA 2012).

A primary role of advertising - at or close to where the brand is available - is to provide a stimulus or cue to shoppers, at or just prior to the moment of making a purchasing decision, by reminding them of the brand information acquired from other advertising media (Moriarty et al. 2012,365). This role can be explained by the well-known principle of cognitive psychology: the encodingspecific principle, i.e., information recall is enhanced when the context in which consumers retrieve information is similar to the context in which they originally encoded/received the information (Tulving and Thomson 1973, 352).

Advertising in broadcast and print media informs consumers about a brand and its features in their homes, typically away from where the final purchase decisions are made. However, consumers are often unable to recall or retrieve this information at the point of purchase or on their way to a store. This is where advertising at/close to the point of purchase plays a crucial role in providing consumers with encoding-specific cues to facilitate the retrieval and recall of the information provided by traditional advertising (Shimp 2010, 591). It is, therefore, crucial that the message and theme be sent via traditional advertising media, and that the encoding-specific cues used in retail advertising at/close to the point-of-purchase be properly integrated to complement each other. Retail-furniture advertising at/close to the point of purchase provides the culmination for an IMC campaign, and increases the probability that shoppers will select a particular brand over alternatives, or indulge in unplanned or impulse buying.

The potential limitations of this medium are the smaller size and relatively lower impact than larger formats, the competing stimuli in the environment that can reduce the impact, as well as the rather high price of advertising space in some upmarket malls or prime locations.

Some of the latest $\mathrm{OOH}$ media types allow for far more specific targeting and potential engagement with an audience. These newer formats - digital and ambient $\mathrm{OOH}$ advertising media in particular - are discussed in the next section.

\section{Alternative $\mathrm{OOH}$ advertising media platforms}

Alternative $\mathrm{OOH}$ advertising includes a variety of new, unconventional media and communication channels, such as digital screens in sports bars, stadiums, interactive displays in shopping malls, advertising displayed on objects placed in unconventional and unexpected contexts (on balloons, bicycles, clothing, tee-markers on a golf course, bill folders, shopping trolleys), promotional street art and graphic-pictorial advertising (graffiti and chalk stencils).

The two major formats in this platform are digital $\mathrm{OOH}$ advertising and ambient $\mathrm{OOH}$ media. The applications of digital $\mathrm{OOH}$ advertising media are different from other $\mathrm{OOH}$ advertising media platforms which display static, printed, non-digital messages without the potential for editorial 
or supporting programme content. For example, liquid crystal display (LCD) screens at airports provide updated news, weather forecasts, sports highlights, entertainment or customised content as well as advertisements.

What makes these newer digital channels different from traditional/one-way $\mathrm{OOH}$ advertising messages is that their customised content allows interaction with the audience in a specific environment (Eun and Kim 2009, 99). The NIKE 2010 campaign, with the theme 'Writing the future', displayed messages on a large, interactive light-emitting diode (LED) screen mounted on the side of the iconic Life Centre Building in the Johannesburg CBD. The audience could engage in and interact with the communication process by sending an SMS on their cell-phone, or messages on social media platforms such as Facebook, Twitter and MXit, to participate. These social messages appeared immediately on the large screen mounted on the building (Graffiti 2010).

Digital $\mathrm{OOH}$ advertising media are similar to traditional outdoor advertising, but digital signage is used to display videos/electronic images on LCD, plasma or standard television screens outside of the home. Usually the screens show advertising, product information or special programmes. For the purpose of this classification, screens that show only textual information or full-length network/cable television programmes without any commercial content or advertising messages, are not included.

Digital $\mathrm{OOH}$ advertising media offer greater flexibility than traditional outdoor advertising, because advertisers can quickly change or adapt their messages, or communicate up-to-date special offers, promotions and prices. The advantage of digital technology is that it also offers more creative and interactive opportunities. Innovative technological developments are constantly being tested and applied (Belch and Belch 2012, 449). Another advantage of this format is the opportunity to include animation, so that, in effect, television commercials are shown outdoors. The latest technology employed in these full-colour and large-format electronic billboards provides superb levels of brightness and resolution on the LEDs. News, weather and relevant information can also be displayed to stimulate audience interest (Provantage 2010).

Currently, the largest digital outdoor advertising board $\left(40 \mathrm{~m}^{2}\right)$ in South Africa is at the corner of Sandton Drive and Rivonia Road, close to Sandton City. The new technology employed here and some of the high-quality $\mathrm{OOH}$ advertising digital platforms can deliver colours of extraordinary brightness and contrast levels - without the diluting influence of full sunshine, as was the case with older technology.

Digital media have recently been introduced in the South African transit media environment, with a view to entertaining and informing commuters. One transit advertising media company, Provantage, installed large plasma screens inside minibus taxis, with Bluetooth technology to broadcast tailor-made programmes to advertise regular features/sponsorships (Provantage 2010). Another company, ComutaNet, erected $12 \mathrm{~m}^{2}$ TV screens at the largest taxi ranks in South Africa, for use by regional or national advertisers who can customise the message of their larger campaign 
for specific local market segments. They also offer an entertaining audio-visual medium when commuters gather together to watch the large screen, for example, during major sporting events (ComutaNet 2011).

Digital $\mathrm{OOH}$ media are not without limitations. In South Africa digital media have limited availability and variety, with most being suitable for indoor use only. The cost of digital media is still relatively high, and there is the potential danger of vandalism when using external digital outdoor advertising.

Ambient $\mathrm{OOH}$ advertising media comprises all unconventional forms of $\mathrm{OOH}$ advertising media that employ alternative and unconventional media in unexpected environments, to transmit messages to a specific audience (Jurca 2010, 327). Unconventional or ambient OOH advertising media forms are numerous and diverse, but what they all have in common is the fact that they allow companies to break through the advertising clutter which prevents a commercial message from reaching the consumer. Thus, ambient $\mathrm{OOH}$ advertising media creators explicitly attempt to surprise people by placing advertisements in unexpected places.

Ambient $\mathrm{OOH}$ advertising media are usually placed in a single location, or in a limited number of public spaces such as outdoor squares, crowded areas or access routes to shopping malls and stores. They are used where the advertised product is sold, or in a context where it is likely to be considered positively (Gambetti 2010,47). These ambient communication messages can be placebased, mobile or displayed on goods used by/exposed to the public. Place-based ambient $\mathrm{OOH}$ media encompass a wide variety of formats that are especially placed where particular groups congregate for a variety of purposes. They can either be interior-based advertising inside stores, shopping malls, restrooms, restaurants, nightclubs or classrooms, or they can include exteriorbased advertising at golf courses, parking garages, petrol stations, sports stadiums, cultural events or live shows (Belch and Belch 2012, 467; Sissors and Baron 2010,268). Mobile ambient $\mathrm{OOH}$ media are not limited to specific spaces and can include blimps, balloons, custom inflatables and projections on any surface which can be used to screen a video or digital image.

Gambetti $(2010,36)$ distinguishes between three-dimensional artefact-based ambient $\mathrm{OOH}$ media and four-dimensional motion-based ambient $\mathrm{OOH}$ media. The former refers to objects positioned in an unusual environment and in an unexpected milieu used for advertising, e.g., messages on shopping bags, plastic cups, handbags, furniture, water bottles, pens, magnets, key rings, bicycles, balloons, drinking straws, cool-drink cans and clothes. The latter comprises all motion-based interactive promotional initiatives which are used to encourage consumers to become involved and participate in the communication process, e.g., Bluetooth posters and touch-screen interactive panels found inside shopping malls. This interactive communication process typically commences with exposure to ambient $\mathrm{OOH}$ media and then moves on to the Internet or cell-phones, where participants express their experience of the event by sharing rumours, photos or videos on social networks. 
Ambient $\mathrm{OOH}$ media include a wide variety of options used for targeting specific audiences at gathering points and high-density consumer areas to advertise relevant products/services. Each of these specialised media vehicles offers advertisers unique benefits as well as disadvantages (Sissors and Baron 2010,268). However, the general advantage is that this advertising can be placed in areas which are most relevant to the product/service being offered, and it is ideal for supporting other advertising media in building/strengthening associations with the theme conveyed in other media (Gambetti 2010, 47). Ambient $\mathrm{OOH}$ advertising media have greater meaning for audiences than advertisements placed out of context. Therefore, selecting the right location and the most relevant environment is crucial, as is profiling the target audience. Ambient advertising is less expensive than more traditional media, and it can deliver excellent results if used correctly (Jurca 2010,325).

Ambient $\mathrm{OOH}$ advertising media are not without limitations. Consumers might not be interested and may ignore messages, no matter how entertaining the surrounding content or how relevant the environment. They might even be distracted by other stimuli in the environment. Even worse, they might regard the advertising as intrusive rather than informative, since such advertising media typically attempt to connect with consumers in places which are normally free of advertisements (Semenescu and Martinsson 2012, 27).

Ambient advertising entails the use of unusual tactics designed to meet conventional communication objectives, hence traditional measures of effectiveness may be inappropriate or at least difficult to identify. Therefore advertisers might not know what their return-on-investment is when using this type of communication (Jurca 2010, 327). Ambient OOH media might not be successful unless properly integrated with an overall marketing and communication strategy, or without proper environmental contextual integration. It might also fail when the creative concept/execution is poor so that it is unable to break through the clutter, grab consumers' attention, and generate wordof-mouth, or when an exaggerated use of creativity cannibalises the brand and merely focuses on the concept (Gambetti 2010, 48).

In summary: The continuous development of $\mathrm{OOH}$ advertising media illustrates the need to acknowledge the role and impact of traditional outdoor advertising media, transit advertising media, street-retail and furniture advertising medias well as alternative $\mathrm{OOH}$ advertising media. For various target markets, these media are used within an IMC approach to strategic media planning.

\section{CONCLUSION AND IMPLICATIONS}

The analysis of the existing academic literature and $\mathrm{OOH}$ advertising media practitioner literature revealed certain differences and similarities with regard to $\mathrm{OOH}$ advertising media. It also revealed the lack of a proper classification framework for the whole new range of $\mathrm{OOH}$ advertising media options available in South Africa. For that reason, a classification framework is proposed. Four major $\mathrm{OOH}$ advertising media platforms - outdoor, transit media, street-and-retail furniture and 
alternative $\mathrm{OOH}$ advertising, all intended to reach consumers outside the home - were included. Each platform was presented and described.

The framework has implications for practitioners as well as academics. It is envisaged that advertisers, marketers and media planners can use this classification as a guideline when evaluating and selecting different media options. Realising all the possibilities may also reduce advertisers' overreliance on traditional outdoor advertising media or billboards, despite the growing number of alternative options that could be more effective in reaching the target audience. $\mathrm{OOH}$ advertising media can now be constantly integrated with the strategic IMC plan, to increase target exposure and ultimately influence buying behaviour.

The application value of the classification framework of $\mathrm{OOH}$ advertising media in a developing context could change global views on the ad hoc and often haphazard use of these media as complementary aids to more traditional advertising media. Emphasising the rapid growth and innovation of the digital and ambient $\mathrm{OOH}$ advertising media formats could have major managerial implications for reaching generation Ys (also known as the Millennials) as well as generation Zs. This will be accelerated by the integration between contemporary $\mathrm{OOH}$ advertising media, and interactive mobile and social media applications. Media planners should take cognisance of $\mathrm{OOH}$ advertising media platforms as an option for reaching and retailing to prospective target markets, by combining these media as opposed to merely employing them in support of traditional media. The economic cost benefits could persuade advertisers to invest in $\mathrm{OOH}$ advertising media.

Marketing scholars and academic institutions should investigate the general economic and social value of these platforms. Contributing findings could enhance the discipline of media planning and strategic integration thereof in the IMC plan. It is envisaged that $\mathrm{OOH}$ advertising media platforms will become a specialised focused discipline within the advertising and marketing contexts.

And, finally, it would be valuable to conduct empirical research (from consumers' and advertisers' perspectives) on the unique strengths and weaknesses of the major $\mathrm{OOH}$ advertising media platforms within a South African context. It is also necessary to explore the potential interactions and the synergy that may exist between these media, when combining different $\mathrm{OOH}$ advertising types in an integrated and overall marketing communication campaign. This variety of unique media options allows advertisers not only to position and reach a mass market, but also to improve their targeting of specific audience profiles.

\section{ACKNOWLEDGEMENT}

This article is based on work supported financially by the National Research Foundation.

\section{REFERENCES}

Babbie, E. and J. Mouton. 2005. The practice of social research. Cape Town: Oxford University Press. 
Belch, G.E. and M.A. Belch. 2012. Advertising and promotion an integrated marketing communications perspective. Ninth edition. Boston: McGraw Hill Higher Education.

Bernstein, D. 2005. Advertising outdoors: Watch this space. London: Phaidon Press.

Bhargava, M., N. Donthu and R. Caron, 1994. Improving the effectiveness of outdoor advertising: Lessons from a study of 282 campaigns. Journal of Advertising Research 34(2) (Mar/Apr): 46-55. Cheong, Y. and K. Kim. 2012. The state of media planning research: A 16-year assessment, 1992-2007. Journal of Current Issues and Research in Advertising 33(2): 227-247.

ComutaNet. 2011. ComutaNet's annual commuter DNA study. Seminar presented by ComutaNet, July, Sandton.

Cooper, D.R. and P. Schindler. 2006. Marketing research. New York: McGraw-Hill.

Davidson, T. 2001. Outdoor advertising: A view from the industry. Paper presented to the $20^{\text {th }}$ Annual South African Transport Conference, South Africa, July 16-20. http://www.xumamedia.com/ downloads/outdooradvertising.pdf (accessed April 20, 2012).

Du Plessis, F., N. Bothma, Y. Jordaan and N. van Heerden. 2010. Integrated marketing communication. Second edition. Claremont, South Africa: New Africa Books.

Du Plooy, A.T. 2012. A framework for the planning and integration of $\mathrm{OOH}$ advertising media in South Africa. Thesis, University of Pretoria.

Du Plooy, A.T. and G. du Plessis. 2011. Exploring the effectiveness of minibus taxis as an advertising medium in an emerging market. Paper presented at the $13^{\text {th }}$ Annual International Conference of the Global Business \& Technology Association, Istanbul, July 12-16.

Duncan, T. 2005. IMC: Using advertising and promotion to build brands. Second edition. Boston: McGraw-Hill.

Eun, H.Y. and H.S. Kim. 2009. An affectability consumer's attitudes toward advertising-based interactive installation in public transportation. Paper presented at the International Association Society of Design Research Conference, October 18-22, Seoul, Korea.

Fachverband Aussenwerbung (FAW). 2013. Out of Home Marketing Association of Germany. http:// www.faw-ev.de/ (accessed May 5, 2013).

FEPE International. 2013. Federation European Publicite Exterieura [Worldwide association of OOH advertising media companies]. http://www.fepe.com/ (accessed May 5, 2013).

Fouché, C.B. and C.L.S. Delport. 2009. In-depth review of the literature. In Research at grass roots: For the social sciences and human service, fifth edition, ed. A.S. de Vos, H. Strydom, C.B. Fouché and C.L.S. Delport. Pretoria: Van Schaik.

Gambetti, R.C. 2010. Ambient communication: How to engage consumers in urban touch-points. California Management Review 52(3): 34-51.

Graffiti. 2010. Impact Media takes Nike to new heights with Life Centre campaign. http://www. bizcommunity.com/PressOffice/PressRelease.aspx?i=120254\&ai=50086 (accessed February 2, 2011).

Jurca, M.A. 2010. The forms of unconventional advertising - a theoretical approach Management and Marketing from Craiova 2: 323-333.

Katz, H. 2010. The media handbook: A complete guide to advertising media selection, planning, research, and buying. Fourth edition. London: Taylor and Francis/Routledge.

Koekemoer, L. 2005. Marketing communication. Lansdowne: Juta.

Lane, R.W., K.W. King and T. Reichert. 2011. Kleppner's advertising procedure. Upper Saddle River, NJ: Prentice Hall. 
Lopez-Pumarejo, T.A. and B. Myles. 2009. The renaissance of outdoor advertising: From Harlem to Hong Kong. American Journal of Business 24(2): 33-40.

Machi, LA. 2009. The literature review: Six steps to success. California: Corwin Press.

Moriarty, S.E., N. Mitchell and W. Wells. 2012. Advertising and IMC: Principles and practice. Upper Saddle River, NJ: Pearson.

Nagel, P. and S. Louw. 2004. Mass media advertisements: Responses to selected advertisements in semi-urban Limpopo. Communicatio 30(2): 98-113.

O'Guinn, T.C., C.T. Allen and R.J. Semenik. 2000. Advertising. Second edition. Cincinnati: SouthWestern College Publishing.

Outdoor Media Association of America (OAAA). 2013. Outdoor media formats. Outdoor Media Association of America. http://www.oaaa.org/marketingresources/outdoormediaformats.aspx (accessed May 5, 2012).

Out of Home Media Association of South Africa (OHMSA). 2013. OOH classification matrix. Out of Home Media Association of South Africa. http://www.ohmsa.co.za/Out_of_Home _Classification_Matrix.pdf (accessed February 6, 2012).

Outdoor Media Association of Australia (OMA Australia). 2013. Outdoor formats. http://www.oma.org. au/using-ooh (accessed May 5, 2013).

Outdoor Media Association of Ireland (OMA Ireland). 2013. The outdoor media in Ireland. http://www. oma.ie/oma/www/index.asp?magpage $=0$ (accessed May 5, 2013).

Out of Home Marketing Association of Canada (OMAC Canada). 2013. OOH media in Canada. http:// www.omaccanada.ca/en/default.omac (accessed May 5, 2013).

Outdoor Media Association of New Zealand (OMANZ). 2013. The formats of OOH advertising. http:// www.omanz.org.nz/power-of-outdoor/outdoor-formats/ (accessed May 5, 2013).

Outdoor Media Centre (OMC). 2013. UK outdoor revenue by environment. Outdoor Media Centre of the United Kingdom. http://www.outdoormediacentre.org.uk/ (accessed May 5, 2013).

Osborne, A.C. and R. Coleman, 2008. Outdoor advertising recall: A comparison of newer technology and traditional billboards. Journal of Current Issues and Research in Advertising 30(11): 13-30.

Outdoor Finland. 2013. The Outdoor Media Association of Finland. http://outdoorfinland.fi/ (accessed May 5, 2013).

Pauwels, L. 2005. Posters, billboards and grassroots media relating to TB and AIDS in the Free State and Lesotho. Acta Academica 1: 337-353.

Primedia. 2010. Outdoor media: The basics. July. Presentation by Primedia Outdoor.

Provantage. 2010. Taxi targeting: Using the nerve centre of the township. Presentation by Provantage Media.

South African Manual for Outdoor Advertising Control (SAMOAC). 2010. Revised South African manual for outdoor advertising control. http://www.environment.gov.za/?q=content/southafrican_ manualfor

outdoor_advertising_control (accessed January 10, 2013).

Semenescu, S. and M. Martinsson. 2012. The 'ambient' strategy to diminish the resistance: A study on ambient advertising and the contemporary consumer resistance towards advertising. Thesis: Lund University http://www.lunduniversity.lu.se/o.o.i.s?id=24965\&postid=2835001 (accessed January 10, 2013).

Shimp, T.A. 2010. Advertising promotion and other aspects of integrated marketing communications. Seventh edition. Mason: South Western Cengage Learing. 
Sissors, J.Z. and R.B. Baron. 2010. Advertising media planning. Seventh edition. New York: McGraw Hill.

Symons, A. 2004. From Toulouse Lautrec to Rodin with some personal impressions. New York: Alfred H. King.

Taylor, C.R. and G.R. Franke. 2003. Business perceptions of the role of billboards in the US economy. Journal of Advertising Research (June): 150-161.

Timms, C. 2012. Transit media: Looking back - moving forward. OH! News (March). http://www. ohmsa.co.za/index.cfm? $\mathrm{x}=$ news\&company $=1 \&$ article $=56 \& \mathrm{nl}=10 \&$ click $=$ web \&subsection $=7 \& 1$ angu=1 (accessed March 30, 2012).

Tulving, E. and D.M. Thomson, 1973. Encoding specificity and retrieval processes in episodic memory. Psychological Review 80: 352-373. http://gureckislab.org/courses/spring12/lhc/readings/Tulving Thompson1973.pdf (accessed January 10, 2013).

Veloutsou, C. and C. O'Donnell. 2005. Exploring the effectiveness of taxis as an advertising medium. International Journal of Advertising 24(2): 217-239.

Wells, W., S. Moriarty, and J. Burnett. 2006. Advertising principles and practice. Edinburgh Gate, England: Pearsons.

Wilson, R.T. and B.D. Till. 2008. Airport advertising effectiveness: An exploratory field study. Journal of Advertising 37(1) (Spring): 59-72. 